\title{
How are patients managing with the costs of care for chronic kidney disease in Australia? A cross-sectional study
}

\author{
Beverley M Essue ${ }^{1 *}$, Germaine Wong ${ }^{2}$, Jeremy Chapman ${ }^{3}$, Qiang Li ${ }^{1}$ and Stephen Jan ${ }^{1}$
}

\begin{abstract}
Background: Chronic kidney disease (CKD) poses a financial burden on patients and their households. This descriptive study measures the prevalence of economic hardship and out-of-pocket costs in an Australian CKD population.
\end{abstract}

Methods: A cross-sectional study of patients receiving care for CKD (stage III-V) in Western Sydney, Australia using a structured questionnaire. Data collection occurred between November 2010 and April 2011. Multivariate analyses assessed the relationships between economic hardship and individual, household and health system characteristics.

Results: The study included 247 prevalent CKD patients. A mean of AUD\$907 per three months was paid out-of-pocket resulting in $71 \%$ ( $n=153$ ) of participants experiencing financial catastrophe (out-of-pocket costs exceeding $10 \%$ of household income). Fifty-seven percent $(n=140)$ of households reported economic hardship. The adjusted risk factors that decreased the likelihood of hardship included: home ownership (OR: 0.32, 95\% Cl: 0.14-0.71), access to financial resources (OR: $0.24,95 \% \mathrm{Cl}: 0.11-0.50$ ) and quality of life (OR: $0.12,95 \%$ Cl: $0.02-0.56)$. The factors that increased the likelihood of hardship included if income was negatively impacted by CKD (OR: 4.80, 95\% Cl: 2.17-10.62) and concessional status (i.e. receiving government support) (OR: 3.09, 95\% Cl: 1.38-6.91). Out-of-pocket costs and financial catastrophe were not found to be significantly associated with hardship in this analysis.

Conclusions: This study describes the poorer economic circumstances of households affected by CKD and reinforces the inter-relationships between chronic illness, economic well-being and quality of life for this patient population.

Keywords: Chronic kidney disease, Economic hardship, Out-of-pocket costs, Australia

\section{Background}

Chronic kidney disease (CKD) management imposes a substantial financial burden on both health systems and on patients and their households. In 2004-05 the total health expenditure for CKD exceeded AUD\$898.7 million in Australia - 1.7\% of the health care budget [1] and similar levels of expenditure are reported for other OECD countries [2,3]. Against this is a background of increasing health expenditure in the form of out-ofpocket payments [4]. Supportive care provided to Australian patients starts at around AUD\$50,000 per annum for dialysis care [5] and while out-of-pocket expenses are only a small proportion of the total cost of

\footnotetext{
* Correspondence: beverley.essue@sydney.edu.au

${ }^{1}$ The George Institute for Global Health, University of Sydney, PO Box M201, Missenden Road, Sydney, NSW 2050, Australia

Full list of author information is available at the end of the article
}

care, their impact can be severe. For example, in a 2006 study of Australian patients receiving dialysis care in Victoria either in a community location or at home, patients paid an average of AUD $\$ 1,237$ and AUD $\$ 480$ out-of pocket annually respectively [6]. These expenses occur at a time when there are interruptions to paid employment and earlier than expected departures from the workforce for the patient and often a family carer [7].

Most studies that estimate out-of-pocket costs only quantify direct costs for treatment and medications [6], overlooking the often substantial costs that are associated with self-management, including: medically related transport, home-care assistance, illness-related home modifications (e.g. for home dialysis set-up) and assistive devices. In Australia, the direct costs of medical care are at least partly covered by health insurance or

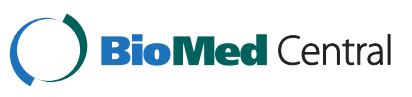


the state (See overview of the Australian health system below). However, self-management expenses are usually paid by patients so previous studies likely under-estimate the true out-of-pocket costs associated with CKD. Furthermore, few studies have quantified the burden more broadly to patients and households in terms of economic hardship and financial distress. In other chronic disease patient populations high rates of economic hardship have been reported based on a reported inability to maintain important living expenses [8-10], medical care costs [11] and with this, compromised adherence to medical care and quality of life $[1,12]$. As CKD disproportionately affects lower socioeconomically disadvantaged individuals it can reasonably be expected that this patient population is also at risk of economic hardship.

\section{An overview of the Australian health and social welfare systems [4]}

The Australian government operates a national health insurance scheme known as Medicare, which subsidises non-public outpatient medical treatment and medications. Medicare rebates a portion of the costs of medical, nursing and allied health services on a fee-forservice basis. Some medical services can be bulk-billed, meaning that the provider charges the same amount as the Medicare rebate, resulting in no out-of-pocket expense. Prescription pharmaceuticals that are approved and listed on the Pharmaceutical Benefit Scheme are also subsidised and individuals are responsible for contributing a co-payment. The Australian government administers safety net programs to cap individual outof-pocket costs for medical services and prescription pharmaceuticals. In addition, the State and Territory governments operate a public hospital system, which provides inpatient services free of charge. They also provide some support for treatment and management aids and services (e.g. transport and appliances) and this is usually means tested. Private health insurance is available for supplementary services such as private hospital treatment, dental services and allied health services and is heavily supported by government subsidies and tax rebates.

The Australian government also operates a separate national welfare system known as Centrelink. Income support through Centrelink is available for age pensions based on means and asset tests and disability pensions based on functional capacity. Pensioners, also referred to as concessional patients, are entitled to receive a number of concessions and subsidies for living, medical and pharmaceutical expenses and are more likely to receive bulk-billed services.

This descriptive study had the following two aims: 1) to quantify the economic burden among patients with
CKD and identify factors that are associated with economic hardship; and 2) to quantify out-of-pocket spending associated with CKD care.

\section{Methods}

\section{Setting and participants}

We recruited English-speaking individuals currently receiving care for CKD III-V in Western Sydney, Australia. An opt-in invitation and a study questionnaire were mailed to a cross-section of individuals, identified by convenience sampling by clinic staff, across the spectrum of illness, including those receiving renal replacement therapy. Individuals either self-administered the questionnaire or completed it with the assistance of a researcher over the phone. The questionnaire was resent to all non-respondents six weeks after the initial mailing and the remaining non-respondents at 10 weeks were re-contacted by telephone with a further reminder.

In addition, all English-speaking individuals receiving dialysis therapy in the three community-based dialysis facilities that served the Western Sydney area were also invited to participate. Individuals who had already completed the questionnaire by post were not invited to participate again. Clinical staff at each centre provided information about the study to those who were interested and individuals either self-completed the questionnaire or completed it with the assistance of a researcher.

The return of a completed questionnaire by post was understood to imply consent to participate in the study. Participants who completed the questionnaire in person with the assistance of a researcher provided written informed consent. This study was approved by the Human Research Ethics Committees of the Sydney West Area Health Service (HREC 2008/5/4.14 (2794)) and the University of the Sydney (12623).

\section{Study questionnaire}

The questionnaire was developed based on the authors' previous work $[9,13,14]$ and included questions that were drawn from existing validated tools [15-18] and covered the following domains: demographics; medical history; quality of life; self-reported chronic illness and disability, household economic circumstances and social connection (i.e. the number of social contacts). The questionnaire domains and variables are described in Additional file 1: Table S1.

\section{The economic burden of CKD}

The economic burden of CKD was measured using the following outcomes: 1) household economic hardship (hardship hereafter) and 2) out-of-pocket costs on medical and health-related expenses.

Hardship was measured using a series of questions about financial stress (e.g. failure to pay basic living and 
medical expenses) and the use of dissaving actions in the previous 12 months. Dissaving behaviour is any action where spending is greater than income thereby reducing already accumulated savings or leading to borrowing to finance the expenditure [17]. Hardship was constructed as a dichotomous variable where a reported inability to make any of the payments posed or the use of a dissaving action was classed as a case of hardship.

Participants were asked about their out-of-pocket costs in the past three months for the following expenses: prescription and non-prescription medications; medical appointments; hospitalisations; medical tests; medicallyrelated transportation (including: ambulance; public, private and subsidised transport); home and self-care assistance; medical equipment and supplies; illness-related home modifications and special food required for an illness-related diet. The burden of out-of-pocket costs was calculated as total out-of-pocket expenditure in the past three months as a proportion of the household's equivalised income for the same quarter. Equivalised household income (income hereafter), was calculated using the Organisation for Economic Cooperation and Development's equivalence scales [19], which make adjustments to actual income to account for households of different size and composition. An out-of-pocket burden greater than 10 percent was defined as financial catastrophe [20].

\section{Statistical analysis}

We conducted descriptive analyses of frequencies for each component of hardship and means, medians and distributions for out-of-pocket spending. Bivariate analyses, using the chi-square test and the independent $t$-test, were used to compare participants with and without hardship for categorical and continuous variables respectively. Given the positive skew of the cost data, the Mann-Whitney $U$ and Kruskal-Wallis one-way ANOVA were used to evaluate differences in median spending in the sample, by stage of illness and by hardship status. Logistic regression was used to identify the factors that were associated with hardship, beginning with a saturated model that included all potential explanatory variables that were associated with hardship at the level of $P<0.25$ in the univariate analysis as well as the variable for age. Variables were assessed individually for significant contribution to the overall model $(P<0.05)$ manually. Effect modification was checked between variables in the model to identify interactions that were significant at the level of $P<0.01$. The Hosmer and Lemeshow goodnessof-fit test was used to check the fit of the final model. Data analysis was conducted using SAS version 9.2.

\section{Results}

\section{Recruitment and participant characteristics}

This study achieved a participation rate of $63 \%, n=247$ (Figure 1). The sample included 23 patients with CKD who were not yet receiving dialysis (pre-dialysis participants hereafter), 199 participants receiving dialysis therapy, dialysing either at home $(\mathrm{n}=70)$ or in a community centre $(n=129)$ and 25 transplant recipients. The mean age of participants was 59 (SD:15) years, 43\% were female $(n=107)$ and $65 \%(n=161)$ were married or living with a partner (Table 1). Participants reported an average of three comorbid conditions and hypertension (69\%, $\mathrm{n}=170)$ and diabetes $(40 \%, \mathrm{n}=99)$ were most commonly reported. The average quality of life score (score between zero and one - a higher score signifies better quality of life) was 0.64 (SD: 0.25) and this did not differ significantly by the stage of CKD. Most participants were out of the workforce, either retired $(n=121)$ or unemployed $(n=76)$ and $74 \%(\mathrm{n}=183)$ reported receiving some form of government support (e.g. income assistance, concessions or subsidies for living expenses) in the past year. In addition, $37 \%(n=91)$ of participants had private health insurance.

Compared to the treated incident renal population in Australia, our sample had a significantly higher proportion of working-aged adults (45-64 years) (Additional file 1: Table S2). The study population may also have been less sick, given the significantly lower prevalence of co-morbid lung disease and cardiovascular disease, and the significantly higher quality of life among dialysis patients. Participants also reported a higher socioeconomic status, signified by higher proportions of home ownership, health insurance coverage and individuals in paid work. However, when compared with the Australian population as a whole, our population of prevalent CKD patients was generally less well off, with more people out of the workforce and lower health insurance coverage, which is consistent with the characteristics of chronically ill patients in Australia [20].

\section{Hardship associated with CKD}

Fifty-seven percent of participants $(n=140)$ had hardship (Figure 2). Paying for utility bills posed the greatest burden with $28 \%(n=69)$ of participants reporting an inability to pay a gas, electricity or telephone bill in the previous 12 months. Nineteen percent $(n=46)$ were unable to pay for medications, $14 \%(n=35)$ were unable to pay co-payments to attend medical appointments and $18 \%(n=44)$ reported missing medical appointments or failed to fill prescriptions in the previous year because they were short of money. Drawing on long-term savings was the main dissaving action reported $(31 \%, n=76)$.

From the multivariable model, after adjusting for age, participants who owned their home (OR: 0.32, 95\% CI: 0.14-0.71), had access to financial resources (OR: 0.24, CI: 0.11-0.50) and had higher quality of life (OR: 0.12, CI: 0.02-0.56) were less likely to have hardship (Table 2). The number of social encounters per week also had a nonsignificant protective effect. The factors that increased the 


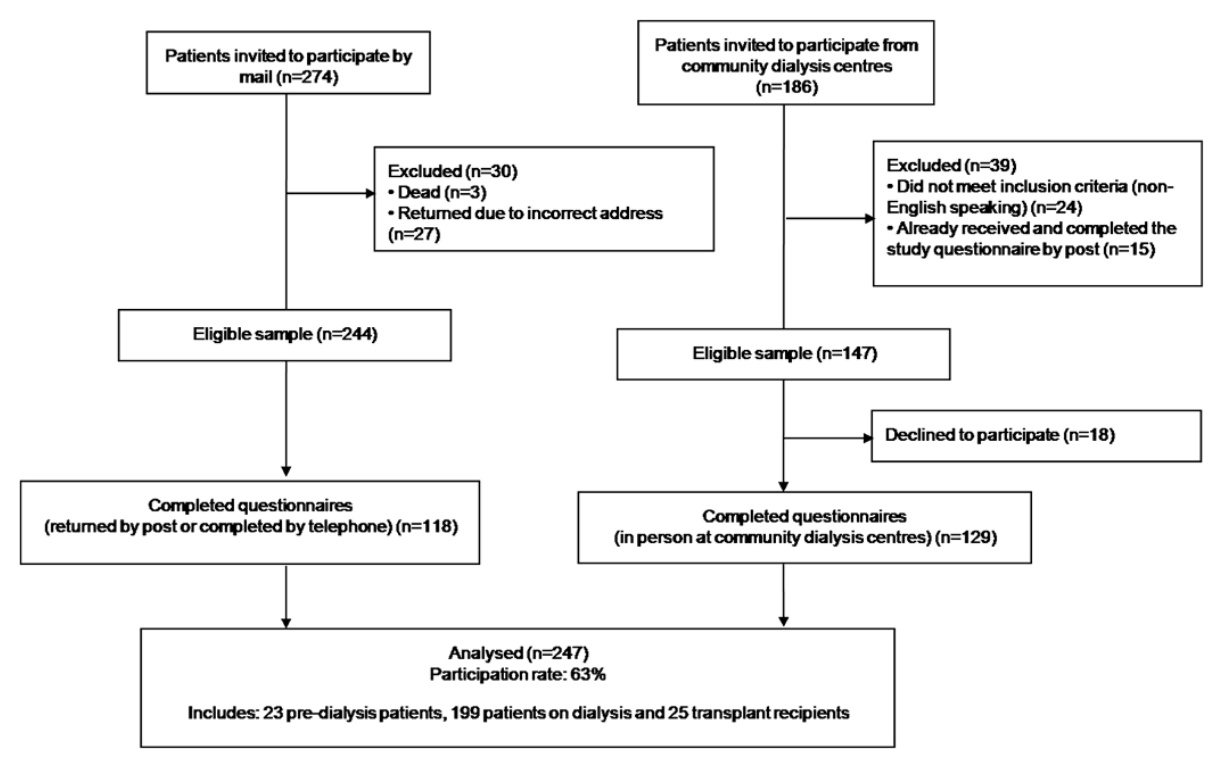

Figure 1 Flow of participants into the study.

odds of experiencing hardship included: if household income was negatively impacted by CKD (e.g. due to early departure from the workforce or change in employment circumstances) (OR: 4.80, CI: 2.17-10.62) and concession status (OR: 3.09, CI: 1.38-6.91). There was no evidence of effect modification among the variables and the final model fit the data well $\left(\chi_{\mathrm{HM}}^{2}=4.48, \mathrm{p}=0.81\right)$.

\section{Relationship between out-of-pocket costs and hardship}

Similar mean out-of-pocket costs were reported for predialysis, dialysis and transplant care - AU\$961 (SD:AU \$1211), AU\$927 (SD:AU\$1089) and AU\$831 (SD:AU $\$ 803$ ) respectively per quarter (AU $\$ 1=\mathrm{US} \$ 1=\mathrm{EU} € 0.73=\mathrm{BG}$ $£ 0.62$; January 2011). At this level of spending, 153 (71\%) participants experienced financial catastrophe. In terms of the sources of out-of-pocket costs, pre-dialysis participants spent the most out-of-pocket in the previous three months on medical care ( $\bar{x}=A U \$ 527, S D: A U \$ 1228)$ (Figure 3). Median spending in this category was significantly higher than that of dialysis and transplant participants $\left(\chi^{2}=22.33, \mathrm{p}<0.0001\right)$. Participants receiving dialysis care and those with a transplant both spent the most on management and supportive care in their home, AU\$538 (SD:AU\$900) and AU\$495 (SD:AU\$663) respectively, which included: home and self-care assistance; medical equipment; illness-related home modifications and illnessspecific diets. Large out-of-pocket costs on illnessrelated home modifications ( $>$ AU\$1000) were reported by a small number of transplant $(\mathrm{n}=2)$ and home dialysis $(n=5)$ participants. When these cases were removed from the analysis, mean spending in this category was reduced to AU\$374 (SD:AU\$449) for those on dialysis and AU\$250 (SD:AUD\$156) for transplant recipients. Finally, participants receiving dialysis also reported significantly higher out-of-pocket spending on medically related transport $\overline{\mathrm{x}}=\mathrm{AU} \$ 312, \mathrm{SD}: \mathrm{AU}$ $\left.\$ 298 ; x^{2}=6.03, \mathrm{p}=0.05\right)$.

The multivariable logistic regression model described above did not identify out-of-pocket costs as a significant determinant of hardship. Table 3 summarises the out-of-pocket costs for each medical and health-related expense category. We found similar levels of spending across all cost categories between those with and without hardship, indicating that those with hardship, despite having less financial resources available to them, maintained levels of expenditure comparable to those not experiencing hardship.

\section{Discussion}

This is the first study to comprehensively measure in patients with CKD in Australia the total out-of-pocket costs and the extent of hardship that are associated with the care of CKD. The prevalence of hardship reported in this study is lower than that found for other chronically ill patient populations in the same region [9]. However, it lies well above the levels that tend to be seen in the Australian population [17] and is consistent with rates of hardship in other chronically ill populations internationally $[10,21]$. In addition, the burden of out-ofpocket costs found in this study, a mean of AUD\$907 in the previous three months is far greater than estimates found in other studies [6], reinforcing wider concerns about the extent to which the Australian health care system relies on individual contributions to fund health care. Individual spending on health care in Australia is high by international, high-income country standards. In 
Table 1 Participant characteristics overall and by hardship status

\begin{tabular}{|c|c|c|c|c|}
\hline & $\begin{array}{r}\text { All participants } \\
(n=247)\end{array}$ & $\begin{array}{r}\text { Hardship } \\
(n=140)\end{array}$ & $\begin{array}{r}\begin{array}{r}\text { No hardship } \\
(n=107)\end{array} \\
\end{array}$ & $P$-value \\
\hline Mean age (years) & 59 (SD:15) & 56 (SD:14) & 62 (SD:15) & 0.001 \\
\hline Gender (Females) & $107 / 246(43 \%)$ & $59(42 \%)$ & $48(45 \%)$ & 0.71 \\
\hline Culturally and linguistically diverse & $85 / 246(35 \%)$ & $54(39 \%)$ & $31(29 \%)$ & 0.13 \\
\hline Married / defacto & $161 / 247(65 \%)$ & $92(66 \%)$ & $69(64 \%)$ & 0.84 \\
\hline Home ownership (yes) & $101 / 246(41 \%)$ & $34(24 \%)$ & $67(63 \%)$ & $<0.0001$ \\
\hline Employment status & & & & $<0.0001$ \\
\hline Employed, full-time & $31 / 245(13 \%)$ & $12(9 \%)$ & $19(18 \%)$ & \\
\hline Employed, part-time (<20hrs/week) & $17 / 245(7 \%)$ & $11(8 \%)$ & $6(6 \%)$ & \\
\hline Unemployed & $76 / 245(31 \%)$ & $60(43 \%)$ & $16(15 \%)$ & \\
\hline Retired & $121 / 245(49 \%)$ & $56(40 \%)$ & $65(61 \%)$ & \\
\hline Education & & & & 0.95 \\
\hline None & $7 / 244(3 \%)$ & $4(3 \%)$ & $3(3 \%)$ & \\
\hline Primary and /or secondary school & $132 / 244(54 \%)$ & $74(53 \%)$ & $58(55 \%)$ & \\
\hline Tertiary & $105 / 244(43 \%)$ & $61(44 \%)$ & $44(42 \%)$ & \\
\hline Income (AUD\$) & & & & 0.39 \\
\hline Under $\$ 379$ per week & $155 / 247(63 \%)$ & $88(63 \%)$ & $67(63 \%)$ & \\
\hline$\$ 380-\$ 579$ per week & $24 / 247(10 \%)$ & $14(10 \%)$ & $10(9 \%)$ & \\
\hline$\$ 580-\$ 769$ per week & $18 / 247(7 \%)$ & $9(6 \%)$ & $9(8 \%)$ & \\
\hline$\$ 770-\$ 959$ per week & $12 / 247(5 \%)$ & $9(6 \%)$ & $3(3 \%)$ & \\
\hline$>\$ 960$ per week & $14 / 247(6 \%)$ & $10(7 \%)$ & $4(4 \%)$ & \\
\hline Don't know/rather not answer & $24 / 247(10 \%)$ & $10(7 \%)$ & $14(13 \%)$ & \\
\hline Co-morbidity (number) & $3 / 247(S D: 2)$ & $3(S D: 2)$ & $2(S D: 2)$ & 0.10 \\
\hline Cancer & $33 / 247(13 \%)$ & $22(16 \%)$ & $11(10 \%)$ & 0.21 \\
\hline Diabetes & $99 / 247(40 \%)$ & $53(38 \%)$ & $46(43 \%)$ & 0.41 \\
\hline Hypertension & $170 / 247(69 \%)$ & $105(75 \%)$ & 65 (61\%) & 0.02 \\
\hline Depression & $65 / 247(26 \%)$ & $41(29 \%)$ & $24(22 \%)$ & 0.23 \\
\hline Cardiovascular disease & $84 / 247(34 \%)$ & $45(32 \%)$ & $39(36 \%)$ & 0.48 \\
\hline Current treatment type & & & & 0.53 \\
\hline Pre-dialysis & $23 / 247(9 \%)$ & $11(8 \%)$ & $12(11 \%)$ & \\
\hline Dialysis & 199/247 (81\%) & $113(81 \%)$ & $86(80 \%)$ & \\
\hline Home & $71 / 199(36 \%)$ & $43(38 \%)$ & $28(33 \%)$ & 0.42 \\
\hline Community location & 128/199 (64\%) & $70(62 \%)$ & $58(67 \%)$ & \\
\hline Transplant recipient & $25 \%(10 \%)$ & $16(11 \%)$ & $9(8 \%)$ & \\
\hline Mean time on dialysis & 5.7 (SD:5.8) & $5.8(S D: 5.4)$ & $5.6(S D: 6.3)$ & 0.83 \\
\hline Mean time since diagnosis, years & 12.7 (SD:11.8) & 12.0 (SD:11.6) & 13.7 (SD:12.2) & 0.30 \\
\hline Quality of life", EQ5D[15] & 0.64 (SD:0.25) & 0.59 (SD:0.23) & 0.70 (SD:0.25) & $<0.001$ \\
\hline Pre-dialysis & $0.62(S D: 0.26)$ & 0.57 (SD:0.23) & 0.66 (SD:0.29) & 0.42 \\
\hline Dialysis & 0.64 (SD:0.24) & 0.59 (SD:0.23) & 0.70 (SD:0.25) & 0.002 \\
\hline Transplant & $0.66(S D: 0.26)$ & 0.59 (SD:0.26) & 0.77 (SD:0.23) & 0.12 \\
\hline Need assistance with ADLs & 150/247 (61\%) & $98(70 \%)$ & $52(49 \%)$ & $<0.001$ \\
\hline Family carer & $102 / 243(42 \%)$ & $70(50 \%)$ & $32(30 \%)$ & 0.003 \\
\hline
\end{tabular}


Table 1 Participant characteristics overall and by hardship status (Continued)

Number of social encounters (per week)

0
$1-3$
$4-6$
$>6$

Catastrophic spending (out-of-pocket spending $>10 \%$ of income)

Mean out-of-pocket spending (AUD\$/quarter)*

Receiving any concessions and /or subsidies

Income negatively impacted by illness

Private health insurance

Able to pay AUD\$2000 for something important in a week (access to financial resources)

Data are presented as either mean ( $\mathrm{SD}=$ standard deviation) or count (\%=proportion).

* $n=229$, missing quality of life data for $n=18$.

${ }^{*}$ Difference in median spending assessed using non-parametric statistical tests.

AU\$1=US\$1=EU€0.73=BGP£0.62; January 2011.

a recent Commonwealth Fund survey of 11 high-income countries, the incidence of out-of-pocket costs exceeding US $\$ 1000$ in the previous year among individual participants was $21 \%$ in Australia - behind only the United States (35\%) and Switzerland (25\%) [22]. The current study makes an important contribution to the literature in this area by improving our understanding of the poorer economic circumstances of households affected by chronic illness and identifying the financial stressors that increase the likelihood of hardship in a CKD population.

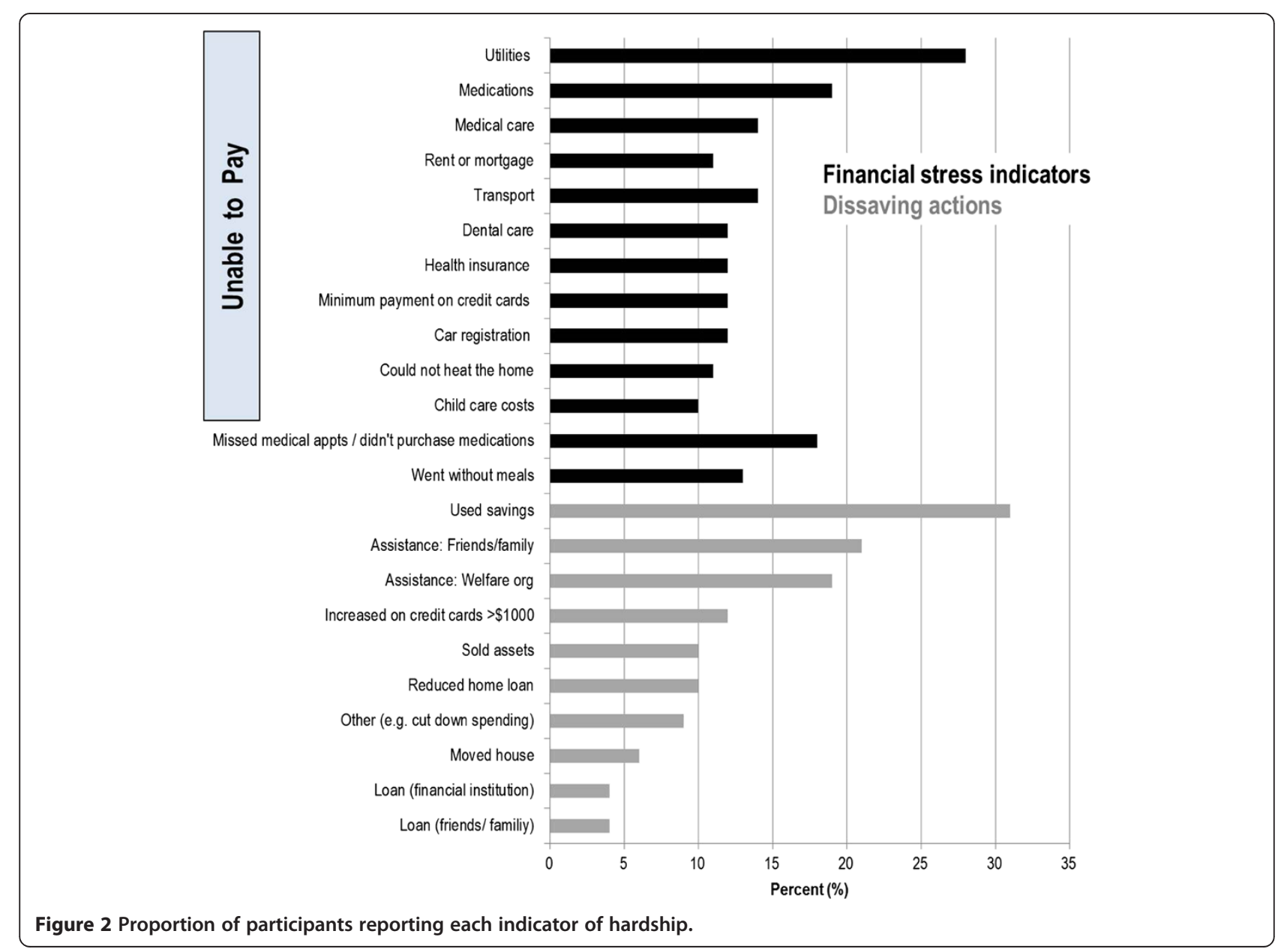


Table 2 Unadjusted and adjusted logistic regression models of correlates of economic hardship

\begin{tabular}{|c|c|c|c|c|}
\hline Covariates & $\begin{array}{r}\text { Unadjusted OR } \\
(95 \% \mathrm{Cl}) \\
\end{array}$ & $P$-value & $\begin{array}{r}\text { Adjusted }^{\mathrm{a}} \text { OR } \\
(95 \% \mathrm{Cl}) \\
\end{array}$ & $P$-value \\
\hline Age & $0.97(0.95-0.99)$ & $<0.001$ & $0.99(0.96-1.02)$ & 0.32 \\
\hline Home ownership (yes) & $0.19(0.11-0.32)$ & $<0.0001$ & $0.32(0.14-0.71)$ & 0.005 \\
\hline Quality of life & $0.14(0.04-0.43)$ & $<0.001$ & $0.12(0.02-0.56)$ & 0.007 \\
\hline Number of social encounters (per week) & & 0.02 & & 0.01 \\
\hline 0 & 1.00 & & 1.0 & \\
\hline $1-3$ & $3.60(1.34-9.69)$ & & $1.90(0.79-4.57)$ & \\
\hline $4-6$ & $4.38(1.70-11.25)$ & & $0.58(0.16-2.11)$ & \\
\hline$>6$ & $2.36(0.71-7.80)$ & & $0.31(0.09-1.09)$ & \\
\hline Receiving concessions and subsidies for living and medical expenses & $10.57(1.47-14.74)$ & 0.001 & $3.09(1.38-6.91)$ & 0.006 \\
\hline Income impacted by illness (due to early departure from work or change in employment) & $5.68(3.27-9.86)$ & $<.0001$ & $4.80(2.17-10.62)$ & 0.0001 \\
\hline Access to financial resources (could pay AUD\$2000 in a week for something important) & $0.12(0.07-0.22)$ & $<.0001$ & $0.24(0.11-0.50)$ & 0.0001 \\
\hline
\end{tabular}

${ }^{\mathrm{a}}$ Hosmer and Lemeshow goodness-of-fit test; $: \chi^{2}: 4.48, \mathrm{p}=0.81$.

The adjusted model was built manually and included all variables associated with hardship at the level of $P<0.25$ in univariate analysis (shown in Table 1).

We found high levels of out-of-pocket costs despite Australia having a comprehensive social health insurance system that is seen to be universal. Previous studies show out-of-pocket costs for treatment can pose serious barriers to adherence to recommended medical care $[4,10,23,24]$, especially for those who are socioeconomically disadvantaged. Patients with hardship were spending similar amounts out-of-pocket overall and in each medical and health related expense category across the stages of CKD. Patients with low means often prioritise paying for medical care over other important expenses [11]. The impact of large out-of-pocket costs for patients with low financial resources can be severe. We found
$13 \%$ of participants reported going without meals, $11 \%$ were unable to heat their homes, $12 \%$ increased the amount owing on their credit cards by greater than \$AUD1000 and $19 \%$ missed medical appointments or failed to fill prescriptions because they were short of money. While not explored in this study, other research has shown that clinicians are often unaware that their patients' are facing difficulty managing out-of-pocket costs [25]. Patients can be reluctant to discuss cost pressures with their health care providers because of a perception that there are few viable solutions to the problem $[10,24,25]$. Clinicians could play a greater role in identifying patients at risk of hardship and linking them into existing social welfare support programs.

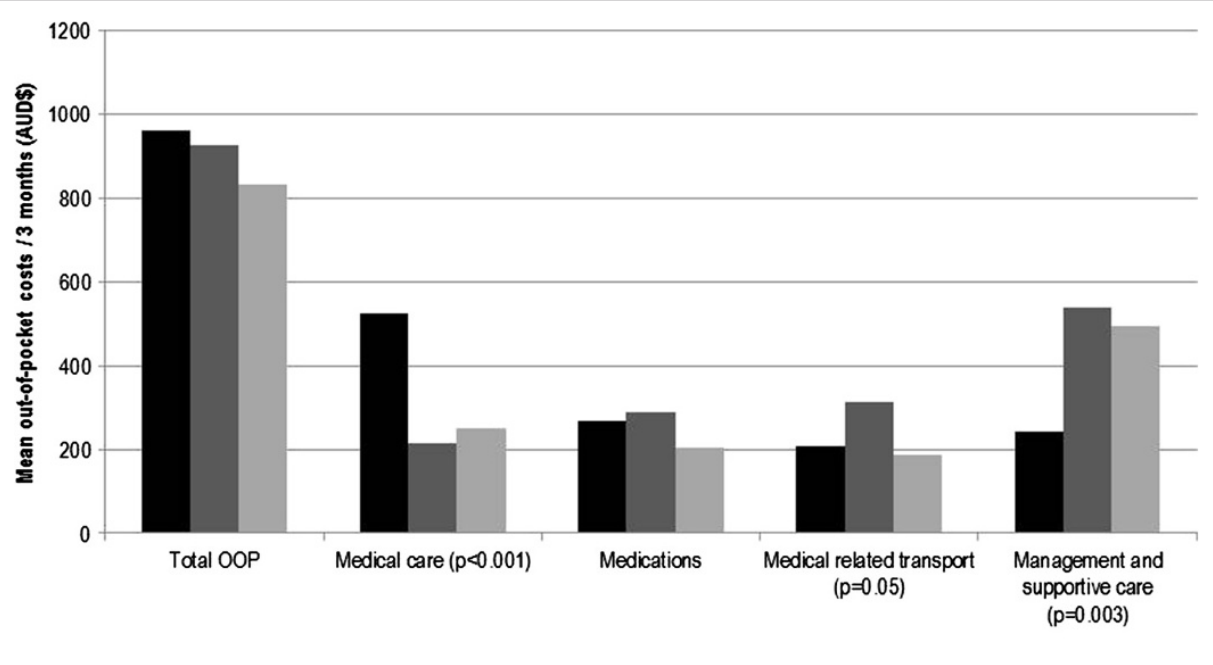

- Pre-dialysis $(n=23) \quad$ Dialysis $(n=199) \quad$ Transplant $(n=25)$

*Averages of each medical and health-related expense category do not equal the 'Total' because there are different denominators in each category

*Difference in median spending assessed using non-parametric statistical test AUS1=US\$1=EU€0.73=BGPE0.62; January 2011

Figure 3 Mean out-of-pocket costs in the previous three months for each medical and health-related expense category by stage of illness. 
Table 3 Summary of out-of-pocket costs by hardship status (out-of-pocket costs in the previous three months)

\begin{tabular}{|c|c|c|c|c|c|c|c|c|}
\hline Out-of-pocket cost category & $\mathrm{n}$ & Minimum & Maximum & Mean (SE) & Mean difference $^{a}$ & $P^{\mathrm{b}}$ & Median (IQR) & $P^{c}$ \\
\hline \multicolumn{9}{|l|}{ All } \\
\hline Hardship & 99 & 15 & 5250 & $876(100)$ & 54 & 0.7 & $655(800)$ & 0.2 \\
\hline No hardship & 136 & 32 & 9460 & $930(96)$ & & & $540(720)$ & \\
\hline \multicolumn{9}{|l|}{ Medical care } \\
\hline Hardship & 100 & 0 & 6150 & $280(84)$ & 76 & 0.5 & $40(200)$ & 0.7 \\
\hline No hardship & 82 & 0 & 5250 & $204(74)$ & & & $53(150)$ & \\
\hline \multicolumn{9}{|l|}{ Medications } \\
\hline Hardship & 128 & 20 & 2000 & $304(27)$ & 57 & 0.08 & $200(280)$ & 0.6 \\
\hline No hardship & 100 & 0 & 1200 & $247(18)$ & & & $200(195)$ & \\
\hline \multicolumn{9}{|l|}{ Transport* } \\
\hline Hardship & 112 & 0 & 1800 & $268(26)$ & -60 & 0.1 & $200(304)$ & 0.2 \\
\hline No hardship & 87 & 0 & 1200 & $328(33)$ & & & $240(380)$ & \\
\hline \multicolumn{9}{|l|}{ Management and supportive care } \\
\hline Hardship & 55 & 15 & 6430 & $552(129)$ & 94 & 0.6 & $265(500)$ & 0.8 \\
\hline No hardship & 33 & 6 & 2710 & $458(113)$ & & & $230(350)$ & \\
\hline
\end{tabular}

AU\$1=US\$1=EU€0.73=BGP£0.62; January 2011.

SE: Standard error; IQR: Interquartile range.

* Medically related transport.

a Mean difference: $\bar{x}$ (hardship) $-\bar{x}$ (no hardship).

${ }^{b}$ Difference in means tested using the independent $t$-test.

c Difference in distribution of medians tested using the Mann Whitney $U$ test.

This study also raises an important implication for clinical practice. In contrast to the published literature on the quality of life of CKD patients [26], we found no differences in quality of life scores across the different stages of illness. However, patients with hardship had lower quality of life across the three stages of CKD and it was significantly lower for patients receiving dialysis care. These findings highlight the inter-relationship between chronic illness, economic wellbeing and quality of life. Maximising quality of life is an important treatment outcome to minimise morbidity and mortality rates in the management of CKD patients. However, maximising quality of life is also associated with other important economic outcomes such as maintaining employment and independence [27]. The clinical management of CKD should take account of these broader outcomes which are relevant to the overall well-being of patients and their households.

This study has limitations. We achieved a participation rate of $63 \%$ and over-sampled patients receiving dialysis care in a community setting. This sample is also drawn from a predominantly low socioeconomic setting. However, comparison of the demographic and socioeconomic characteristics of our sample with the treated incident renal population in Australia and a national census of patients on dialysis shows that our sample is younger, less sick and has a higher proportion in patients still in paid employment (Additional file 1: Table S2). We have likely under-estimated the true economic impact of
CKD for patients who are socioeconomically disadvantaged. In addition, the observed non-response is likely related to both outcomes and to hardship status, giving a potential for bias in association. We did not sample non-English speaking participants. The extent of hardship may be even more pronounced in these groups because of inherent reasons, including their ability to access and navigate existing social welfare supports. Finally, we measured hardship at one time point. It is likely that patients employ different coping strategies over time to improve their circumstances. A prospective design would allow assessment of the change in financial circumstances and understand better the direction of causation. In this study, the aim was instead to describe the lived experience of patients in which economic hardship, poor health and other aspects of social disadvantage co-exist. Given that our study population had been receiving dialysis for a mean of five years and were on average 12 years past their diagnosis, our results likely reflect the situation of the established 'steady state' for the households affected, demonstrating a need for early interventions to assist households to better cope with the negative economic sequelea of CKD.

\section{Conclusion}

This study found a considerable proportion of patients face hardship and high out-of-pocket spending associated with the care and management of CKD in Australia. This research raises important practice implications 
for clinicians who could play a greater role in identifying and supporting patients who are experiencing hardship, particularly in settings that rely heavily on out-of-pocket costs to fund CKD treatment, such as in the US. It also provides a basis for further investigation of the additional supports required to better assist households affected by CKD, which would likely also be of benefit to other chronically ill patient populations.

\section{Additional file}

Additional file 1: Table S1. Summary of domains included in the study questionnaire. Table S2. Comparison of demographic and socio-economic characteristics between the study participants receiving renal replacement therapy with the treated incident renal population in Australia.

\section{Competing interest}

The authors declare that they have no competing interests.

\section{Authors' contributions}

$\mathrm{BE}, \mathrm{SJ}, \mathrm{GW}$ and JC conceived of the study and participated in its design and coordination. BE collected all data, conducted data analysis and wrote the first draft of the paper. QL provided statistical expertise and guidance. All authors read and approved the final manuscript.

\section{Acknowledgements}

We thank all of the participants who contributed to this study and the nursing and medical staff of the renal clinics for their assistance with recruitment. This study was funded with assistance from an Australian National Health and Medical Research Council Capacity Building Grant (grant no. 571372). BE was funded by a Canadian Institutes of Health Research Doctoral Research Award while completing this study.

\section{Author details}

${ }^{1}$ The George Institute for Global Health, University of Sydney, PO Box M201, Missenden Road, Sydney, NSW 2050, Australia. ${ }^{2}$ Children's Hospital at Westmead, Centre for Kidney Research, Westmead Hospital, The Research Building, Level 2, Sydney, NSW 2145, Australia. ${ }^{3}$ Westmead Hospital, Acute Interventional Medicine and Renal Services, Darcy Road, Westmead, Sydney, NSW 2145, Australia.

Received: 28 May 2012 Accepted: 21 December 2012 Published: 10 January 2013

\section{References}

1. Australian Institute of Health and Welfare: Health care expenditure on chronic kidney disease in Australia. Canberra: AlHW; 2009:117. Cat. no. PHE.

2. Baboolal K, McEwan P, Sondhi S, et al: The cost of renal dialysis in a UK setting-a multicentre study. Nephrol Dial Transplant 2008, 23:1982-1989.

3. Zelmer $\mathrm{J}$ : The economic burden of end-stage renal disease in Canada. Kidney Int 2007, 72:1122-1129.

4. Australian Institute of Health and Welfare: Health expenditure Australia: 2010-11. Health and welfare expenditure series no. 47. Cat. no. HWE 56. Canberra: AlHW; 2012.

5. Australian Institute of Health and Welfare: Dialysis and kidney transplantation in Australia: 1991-2010. Canberra: AlHW; 2012. Cat. no. PHE 162.

6. Healthcare Management Advisors Pty Ltd and Victorian Department of Human Services: Renal Dialysis Costing and Funding Review. Draft Final Report. Collingwood: Healthcare Management Advisors Pty Ltd; 2006. Available from: http://docs.health.vic.gov.au/docs/doc/ B287F4FEF5FE63ECCA2578E20006ACFA/\$FILE/renal-cost-finrep-draft12dec. pdf [cited: 11 December 2011].

7. Muehrer RJ, Schatell D, Witten B, et al: Factors affecting employment at initiation of dialysis. Clin J Am Soc Nephrol 2011, 6:489-496.

8. Alexander GC, Casalino LP, Meltzer DO: Patient-physician communication about out-of-pocket costs. JAMA. 2003, 290:953-958.
9. Essue B, Kelly P, Roberts M, et al: We can't afford my chronic illness! The out-of-pocket burden associated with managing chronic obstructive pulmonary disease in western Sydney, Australia. J Health Serv Res Pol 2011, 16:226-231.

10. Piette JD, Heisler M, Wagner TH: Problems paying out-of-pocket medication costs among older adults with diabetes. Diabetes Care 2004, 27:384-391.

11. Jeon Y-H, Essue B, Jan S, et al: Economic hardship associated with managing chronic illness: a qualitative inquiry. BMC Heal Serv Res 2009, 9:182.

12. Jan S, Essue BM, Leeder SR: Falling through the cracks: the hidden economic burden of chronic illness and disability on Australian households. MJA 2011, 196:1-3.

13. Hackett ML, Glozier NG, Jan S, et al: Psychosocial Outcomes in StrokE: the POISE observational stroke study protocol. BMC Neurol 2009, 9. doi:10.1186/1471-2377-9-24.

14. Hackett ML, Glozier NS, Martiniuk AL, et al: Sydney epilepsy incidence study to measure illness consequences: the SESIMIC observational epilepsy study protocol. BMC Neurol 2011, 11. doi:10.1186/1471-2377-11-3.

15. The EQ-5D: a standardised instrument for use as a measure of health outcome. Available from: http://www.euroqol.org/.

16. Banks E, Redman S, 45 and Up Study Collaborators: Cohort profile: the 45 and up study. Int J Epidemiol 2008, 5:941-947.

17. Australian Bureau of Statistics: 2010 General Social Survey: Summary results. Canberra: ABS. Cat no. 4159.0; 2011

18. Grootaert C, Narayan D, Jones VN, et al: Measuring Social Capital: an integrated questionnaire. Working paper No. 18. Washington: The World Bank; 2004.

19. de Vos K, Zaidi MA: Equivalence scale sensitivity of poverty statistics for the member states of the European Community. Review of Income and Wealth 1997, 43:319-333.

20. Berki SE: A look at catastrophic medical expenses and the poor. Health Aff (Millwood). 1986, 5:138-145.

21. Gordon EJ, Prohaska TR, Sehgal AR: The financial impact of immunosuppressant expenses on new kidney transplant recipients. Clin Transplant 2008, 22:738-748.

22. Schoen C, Osborn R, Squires D, et al: How health insurance design affects access to care and costs, by income in eleven countries. Health Aff 2010, 29:2323-2334

23. Hirth RA, Greer SL, Albert JM, et al: Out-Of-Pocket Spending And Medication Adherence Among Dialysis Patients In Twelve Countries. Heal Aff 2008, 27:89-102.

24. Hynd A, Roughead EE, Preen DB, et al: The impact of co-payment increases on dispensings of government-subsidised medicines in Australia. Pharmacoepidemiology and Drug Safety 2008, 17:1091-1099.

25. Piette JD, Heisler M, Wagner TH: Cost-related medication underuse: do patients with chronic illnesses tell their doctors? Arch Intern Med 2004, 164:1749-1755.

26. Liem YS, Bosch JL, Myriam Hunink MG: Preference-based quality of life of patients on renal replacement therapy: a systematic review and metaanalysis. Value Health 2008, 11:733-741.

27. Blake C, Codd MB, Cassidy A, et al: Physical function, employment and quality of life in end-stage renal disease. J Nephrol 2000, 13:142-149.

doi:10.1186/1471-2369-14-5

Cite this article as: Essue et al:: How are patients managing with the costs of care for chronic kidney disease in Australia? A cross-sectional study. BMC Nephrology 2013 14:5.

\section{Submit your next manuscript to BioMed Central and take full advantage of:}

- Convenient online submission

- Thorough peer review

- No space constraints or color figure charges

- Immediate publication on acceptance

- Inclusion in PubMed, CAS, Scopus and Google Scholar

- Research which is freely available for redistribution 